\title{
Gamma Knife and Chemoradiotherapy Applied Nasopharyngeal Cancer Patient Observed Radiation-Induced Optic Neuropathy and Retinopathy: A Case Report
}

\author{
Alsan Cetin I*, Taka U', Sahin $\mathbf{O}^{1}$, Ozen $\mathrm{Z}^{2}$, Abacıoglu $\mathbf{U}^{2}$ and Kazokoglu $\mathbf{H}^{1}$ \\ ${ }^{1}$ Department of Ophthalmology, Marmara University, Fevzi cakmak mah. Inonu cad. No:41, Ustkaynarca/Pendik Postcode 34903, Turkey \\ ${ }^{2}$ Department of Radiation Oncology, Marmara University, Fevzi cakmak mah. Inonu cad. No:41, Ustkaynarca/Pendik Postcode 34903, Turkey
}

\begin{abstract}
Introduction: Radiotherapy is treatment for nasopharyngeal carcinoma, and concurrent chemoradiotherapy has been shown to prolong survival. Radiation-induced is a dramatic late complication of radiation therapy for tumors involving structures in the vicinity of the visual pathway. The association between dose and radiation retinopathy is well established.

Case presentation: The patient was a 48-year-old turkish man. A case history of bilateral radiation-induced optic neuropathy and retinopathy, 105 months after combined treatment by chemotherapy, conformal radiotherapy and 62 months after gamma knife for a nasopharyngeal carcinoma.
\end{abstract}

Conclusion: We recommend that all patients undergoing radiotherapy, which is likely to result in retinal irradiation, be warned of risk of radiation retinopthy of the dose applied.

Keywords: Nasopharyngeal neoplasm; Radiotherapy; Radiation injuries; Radiation-induced optic neuropathy; Retinopathy

\section{Introduction}

Radiotherapy is mainstay treatment for early nasopharyngeal carcinoma, and concurrent chemoradiotherapy has been shown to prolong survival in advanced disease [1-2]. Radiation retinopathy first described by Stallard' and Foster Moore in the 1930s [3]. Radiationinduced is a dramatic late complication of radiation therapy for tumors involving structures in the vicinity of the visual pathway, such as those originating from the paranasal sinuses, nasopharynx and pituitary fossa, and meningioma [4-14]. Radiation retinopathy is an occlusive microangiopathy occurring with variable latency after exposure of the retina to ionizing radiation. The initial pathologic events leading to clinical radiation retinopathy are endothelial cell loss and closure of retinal capillaries [15]. Radiation optic neuropathy is an uncommon and may progress to complete blindness especially is seen in patients whom both optic nerves or the chiasm are exposed to radiation [16]. This case report presents the medical history of a 48 year-old male, developing bilateral radiation-induced optic neuropathy and retinopathy 105 months after combined treatment by chemotherapy, conformal radiotherapy and 62 months after gamma knife for a nasopharyngeal carcinoma.

\section{Case Presentation}

A previously healthy 48-year-old turkish man was referred to the department headache, double vision, facial numbness of the complaint. Nasopharyngeal endoscopy revealed left posterior wall of the nasopharynx ulsero-vegetative mass. Magnetic resonance (MRI) in the left parapharyngeal, nasopharyngeal air column which narrowed the pterygoid muscle that holds $3.5 \times 4.5 \mathrm{~cm}$ in size the left cavernous sinus and sphenoid sinus filling the middle cranial mass was noted. The case was diagnosed as undifferentiated carcinoma by endoscopic punch biopsy.

According to the AJCC recommendations, the patient was classified as having a T4N0M0 stage- IVA cancer of nasopharynx. He was treated with primary radiotherapy and concurrent cisplatin. For conformal radiotherapy linear accelerator (Saturn 42, GE) was performed using the photon energy $6 \mathrm{MV}$. The target volume was determined by preoperative CT or MRI. The patient was placed in a supine position using an immobilizing head and neck thermoplastic mask. The target volume was irradiated by $6 \mathrm{MV}$ photons with 2 Gy per a day, 5 days in a week. Two lateral parallel opposed fields for the primary and upper cervical lymph nodes (dose prescribed to the midline), and an anterior abutted supraclavicular field for the lower cervical lymph nodes (dose prescribed at a depth of $3 \mathrm{~cm}$ ) were used in $46 \mathrm{~Gy}$. After that, two lateral parallel opposed fields for nasophangeal area plus $2 \mathrm{~cm}$ were used $24 \mathrm{~Gy}$. The dose was prescribed according to the International Commission on Radiation Units and Measurements to determine the treatment area (ICRU) 50 recommendations. 100\% isodose line in the middle of the tumor is selected. Supra field, neck and nasopharyngeal $46 \mathrm{~Gy}, 24 \mathrm{~Gy}$ nasopharyngeal with boost total $70 \mathrm{~Gy}$ in 35 fractions a 8 week course was underwent.

Chemotherapy regimen was decided by evaluating the patient's general status. During the treatment was applied simultaneously with cisplatin $40 \mathrm{mg} / \mathrm{m}^{2} /$ weekly. During the treatment 6 and 7 week due to hematological toxicity of chemotherapy could not be granted and G-CSF treatment was performed. Acute side effects were grade II mucositis was found in. Regression was limited to the patient follow-

*Corresponding author: Ilknur Alsan Cetin, Department of Radiation Oncology Marmara University, Fevzi cakmak mah. Inonu cad. No:41, Ustkaynarca/ Pendik 34903, Turkey, E-mail: ilknurcet@gmail.com

Received April 27, 2013; Accepted May 20, 2013; Published May 22, 2013

Citation: Alsan Cetin I, Taka U, Sahin O, Ozen Z, Abacıoglu U, et al. (2013) Gamma Knife and Chemoradiotherapy Applied Nasopharyngeal Cancer Patient Observed Radiation-Induced Optic Neuropathy and Retinopathy: A Case Report. J Nucl Med Radiat Ther 4: 152. doi:10.4172/2155-9619.1000152

Copyright: (c) 2013 Alsan Cetin I, et al. This is an open-access article distributed under the terms of the Creative Commons Attribution License, which permits unrestricted use, distribution, and reproduction in any medium, provided the original author and source are credited. 
Citation: Alsan Cetin I, Taka U, Sahin O, Ozen Z, Abacıoglu U, et al. (2013) Gamma Knife and Chemoradiotherapy Applied Nasopharyngeal Cancer Patient Observed Radiation-Induced Optic Neuropathy and Retinopathy: A Case Report. J Nucl Med Radiat Ther 4: 152. doi:10.4172/21559619.1000152

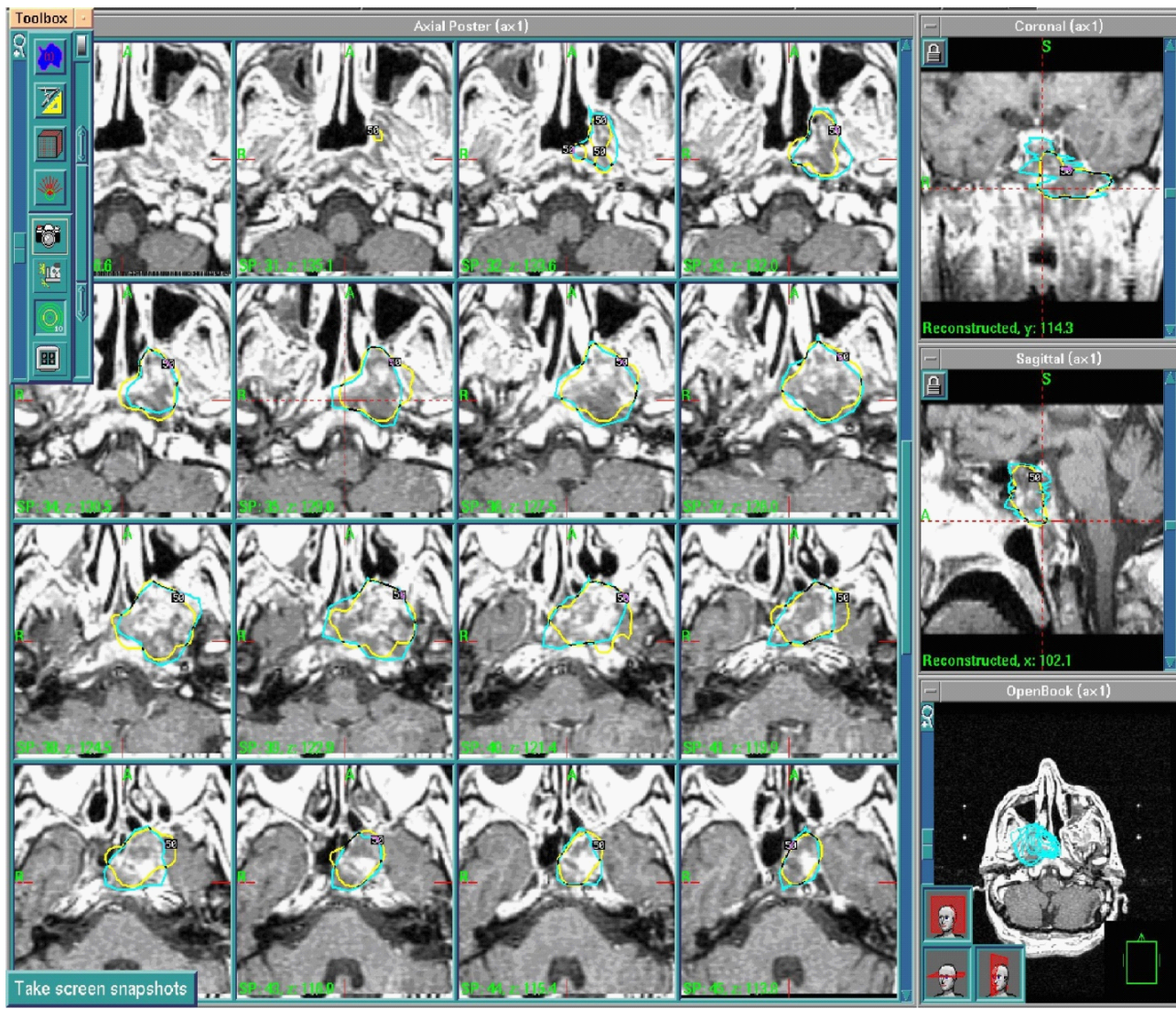

Figure 1: Applied to the tumor dose distribution with gamma knife

up. After 42 months, significantly enhancing bilateral infiltrates of the right cavernous sinus mass had been detected in MRI and $50 \%$ of the field, 16 Gy isodose (32 Gy maximum dose) was applied to the Gamma Knife radiosurgery (Figure 1) Chiasm dose; $2.8 \mathrm{~Gy}$, with bilateral optic nerve dose; $5 \mathrm{~Gy}$, pons dose; 4.9 Gy was. After 8 years of treatment, our patient developed visual loss.

The patient visited with a complaint of gradually decreased visual acuity in his right eye, while that was 56-year-old. At the first ophthalmological examination, the corrected best visual acuities in the right eye (OD) and the left eye (OS) were 0.3 and 0.4 respectively with anisocoria. Slit lamp examination revealed that there were bilateralnuclearcataract and pseudoexfoliation in the anterior segment. The funduscopic examination revealed vitreous hemorrhage, macular edema with ring of circinate hard exudates involving the center of the macula in the OD (Figure 2a) and flame shaped hemorrhages inferotemporal arcade with in the OS (Figure 2b). Fluorescein angiography showed extensive ischemic areas with capillary nonperfusion, telangectasias, dilated capillaries adjacent to the areas of capillary closure in both fundus (Figures $3 \mathrm{a}$ and $3 \mathrm{~b}$ ), and new vesel formation in the left fundus (Figure 3c). The optical coherence tomography (OCT) showed cystoid macular edema formation (Figures $4 \mathrm{a}$ and $4 \mathrm{~b}$ ) and central retinal thickness were $610 \mu \mathrm{m}$ to $343 \mu \mathrm{m}$.

Past medical history included radiation therapy for nasopharyngeal carcinoma 8 years ago. He had no medical history of diabetes, hypertension and systemic vascular disease. Three years before this visit, his visual acuity decreased acutely in his OS and was treated for vitreous hemorrhage in another clinic.
To reduce the macular edema, we have performed off-label intravitreal bevacizumab $(2.5 \mathrm{mg} / 0.1 \mathrm{ml})$ injection in both eyes which were a week apart. Our methods was introduced through the pars plana (through a 30-gauge needle) and the patient received topical antibiotic therapy for 1 week. Both eyes were treated with scatter panretinal photocoagulation in the following weeks. He received 811 burns of 300 $\mu \mathrm{m}$ for OD and 300 burns of $500 \mu \mathrm{m}$ for OS in a session. The patient didn't continue for following sessions so his next visual acuity couldn't be evaulated.

The patient re-applied to our clinics for visual disturbance in his left eye after 3 months. The visual acuity was $0.40 \mathrm{OD}$ and $0.008 \mathrm{OS}$. Fundus examination showed pale optic disc in both eyes (Figures $5 \mathrm{a}$ and $5 b$ ). In addition, there were altitudinal defects in his visual field of both eyes (Figure 6). We have considered this new situation of the patient as a recent onset ischemic optic neuropathy.

In the last examination of the patient, the vision was $0.40 \mathrm{OD}$ and 0.40 OS. The circinate hard exudates and pale optic discs were still present but hemorhage had disapeared in fundus ohthalmoscopy. The angiogram showed reperfusion little of the retinal cappilary system in both eyes and neovascularisation of disc in OS (Figure 7). Central retinal thicknesses were $472 \mu \mathrm{m}$ to $425 \mu \mathrm{m}$ (Figures $4 \mathrm{c}$ and $4 \mathrm{~d}$ ). The overall ophthalmic findings seemed fully compatible with bilateral radiation-induced optic neuropathy and retinopathy.

\section{Discussion}

Factors that appear important in the pathogenesis of radiation 
Citation: Alsan Cetin I, Taka U, Sahin O, Ozen Z, Abacıoglu U, et al. (2013) Gamma Knife and Chemoradiotherapy Applied Nasopharyngeal Cancer Patient Observed Radiation-Induced Optic Neuropathy and Retinopathy: A Case Report. J Nucl Med Radiat Ther 4: 152. doi:10.4172/21559619.1000152

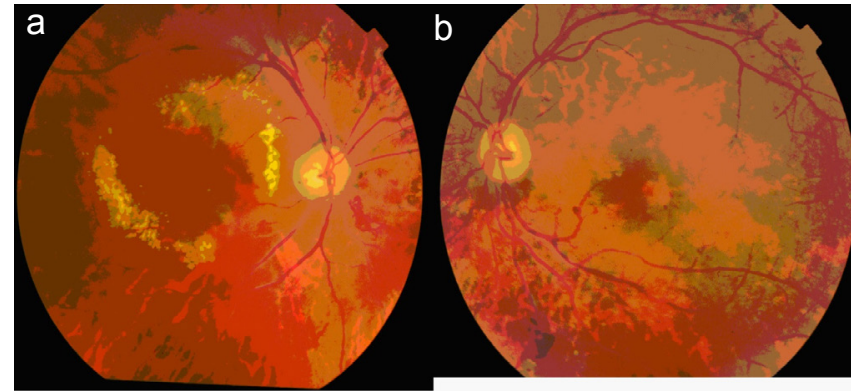

Figure 2: The colour fundus photographs show circinate hard exudates (right eye) and flame shaped hemorrhages (left eye).
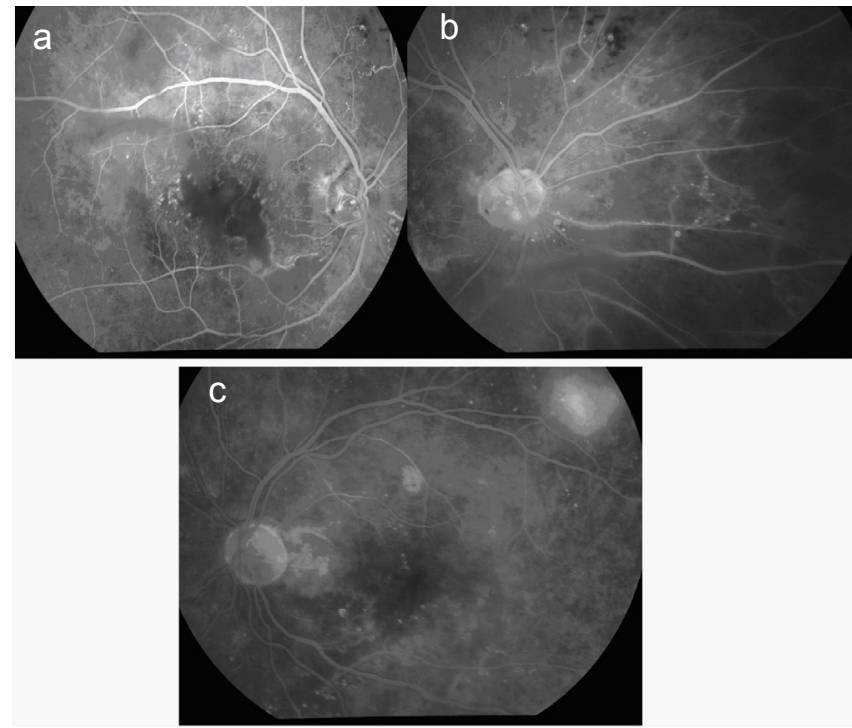

Figure 3: Fluorescein fundus angiography. 2a; telangectases (right eye), 2b; ischemic areas with capillary nonperfusion $\left(^{*}\right)$ and capillary closure (right eye), 2c; neovasculazation at the supero temporal (left eye).

a

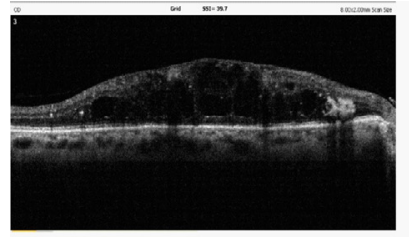

C

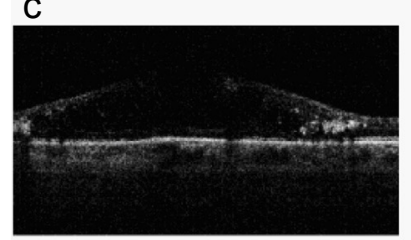

b

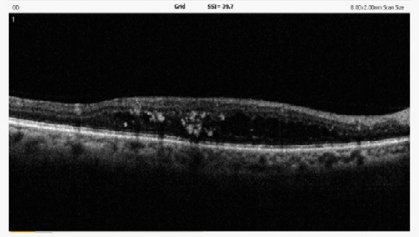

d

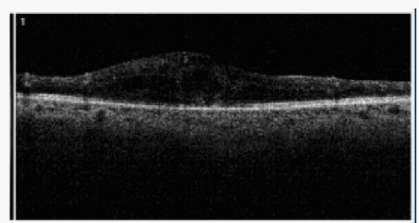

Figure 4: Optical coherence tomogram shows cystoid macula edema (a-b) Six months after intravitreal bevacizumab injection (c-d).

retinopathy include total radiation dosage, fraction size, area irradiated, concomitant chemotherapy, and preexisting vasculer disorders $[11,17]$. The association between dose and radiation retinopathy is well established [10-11]

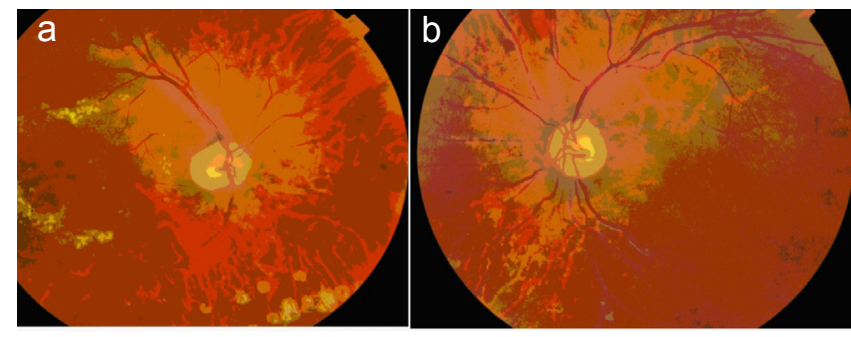

Figure 5: The colour fundus photographs show pale optic disc in both eyes 3 months after first examination.
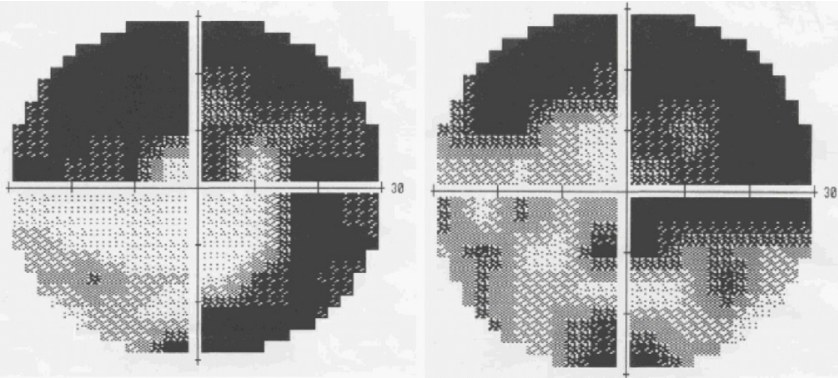

Figure 6: Visual fields show altitudinal defects in both eyes.
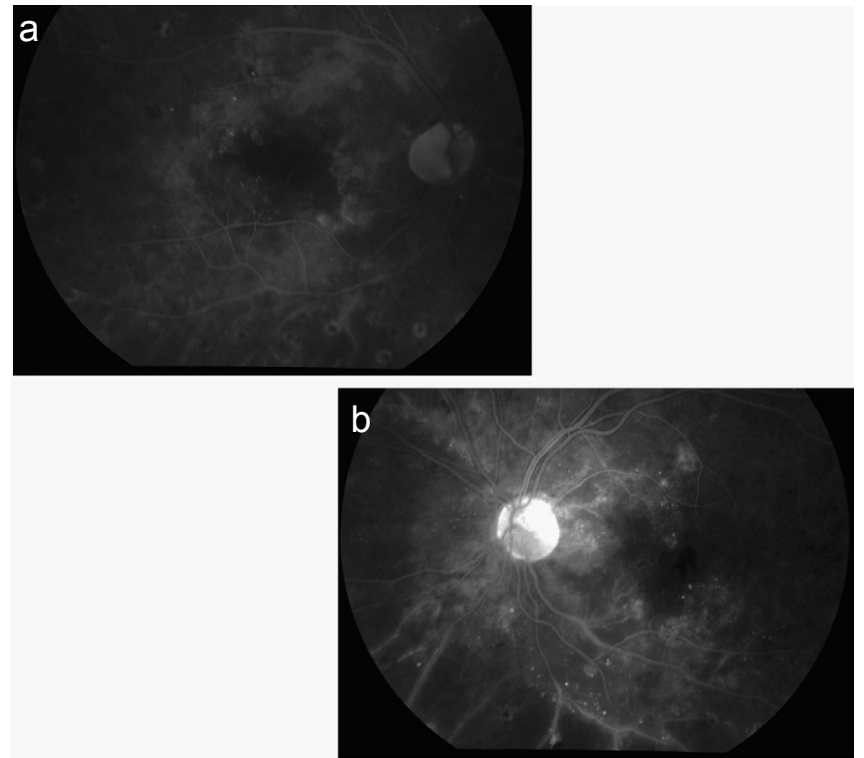

Figure 7: Fluorescein fundus angiography shows dilated capillaries and capillary closure is lessened in both eyes and neovascularisation of disc in left eye.

Takeda et al. [11] found that eyes receiving more than 50 Gy to greater than $60 \%$ of the retina were more likely to develop radiation retinopathy. According to Kline et al. [18] the risk of RON (radiationinduced optic neuropathy) increases with total radiation doses of more than 50 Gy or a single fraction of greater than 2 Gy using fractionated radiotherapy. Additionaly radiosurgery (eg. Gamma Knife) doses of greater than 8 Gy and concomitant chemotherapy raise the risk of RON [19].

Monroe et al. [14] report the largest systemic analysis of factors associated with radiation retinopathy after treatment of patients with 
Citation: Alsan Cetin I, Taka U, Sahin O, Ozen Z, Abacıoglu U, et al. (2013) Gamma Knife and Chemoradiotherapy Applied Nasopharyngeal Cancer Patient Observed Radiation-Induced Optic Neuropathy and Retinopathy: A Case Report. J Nucl Med Radiat Ther 4: 152. doi:10.4172/21559619.1000152

Page 4 of 4

head and neck cancer. Total dose the retina, age, and dose fractionation were the factors most predictive of retinopathy, with hyperfractionation reducing the incidence by more than half among patients who received more than 50 Gy. The gamma knife treatment was performed in our patient as a single dose of hypofractionated.

Clinically, radiation retinopathy may develop after ionising radiation reaches the posterior segment of the eye by either local treatment. The radiation may be given for local intraocular lesions or for adjacent extraocular lesions. The severity of the retinopathy is thought to be related to total radiation dosage and to the fractionation of that dosage. The total time of the treatment and the latent period between the irradiation is also of significance [20].

The histopathology of radiation induced ischaemic vasculopathy reveals the destruction of the endothelial cells and pericytes that maintain blood vessel walls [21]. Whereas the histopathology of RON is unknown but it is presumbly ischemic because of the demyelination reactive astrocytes, and obliterative endarteritis seen on histopathologic specimens [18].

Fluorescein angiography was demonstrable and useful in more accurately delineating the vascular abnormalities present [3], so in our case was significant lesions found with fluorescein that could be seen by ophthalmoscopy.

Radiation retinopathy is classficated as a four stage by Finger [21]. This classification is predicted prognosis of radiation retinopathy. In our case there was last stage (stage 4) that present vitreous haemorrhage, large areas of retinal ischaemia and neovascularisation. So the prognosis for vision and globe salvage was worse.

Laser treatment and intravitreal injection was considered at radiation if ischeamic changes and macular edema devoleped. We performed intravitreal injection and panretinal photocoagulation for treatment of radiation retinopathy and showed reduction macular edema with OCT. No randomized, masked, controlled clinical trials (class levidence) to treat RON exist for any proposed therapy of RON. Previous studies have reported the use of intravenous corticosteroids, anticoagulation, intravitreal vascular endothelial growth factor inhibitors, optic nerve sheath fenestration, and hyperbaric oxygen therapy with scattered success [22]. We didn't have any treatment to our patient for radiation optic neuropathy.

We maintained eyes using the lateral areas for conformal radiotherapy but mustn't forget the factor of simultaneous chemotherapy and applied to the patient the dose of gamma knife.

\section{Conclusion}

We recommend that all patients undergoing radiotherapy, which is likely to result in retinal irradiation, be warned of risk of radiation retinopathy of the dose applied.

\section{References}

1. Al-Sarraf M, Reddy MS (2002) Nasopharyngeal carcinoma. Curr Treat Options Oncol 3: 21-32.
2. Chan AT, Teo PM, Johnson PJ (2002) Nasopharyngeal carcinoma. Ann Oncol 13: $1007-1015$

3. Thompson GM, Migdal CS, Whittle RJ (1983) Radiation retinopathy following treatment of posterior nasal space carcinoma. Br J Ophthalmol 67: 609-614.

4. Aristizabal S, Caldwell WL, Avila J (1977) The relationship of time-dose fractionation factors to complications in the treatment of pituitary tumors by irradiation. Int J Radiat Oncol Biol Phys 2: 667-673.

5. Goldsmith BJ, Rosenthal SA, Wara WM, Larson DA (1992) Optic neuropathy after irradiation of meningioma. Radiology 185: 71-76.

6. Guy J, Mancuso A, Beck R, Moster ML, Sedwick LA, et al. (1991) Radiationinduced optic neuropathy: a magnetic resonance imaging study. J Neurosurg 74: 426-432.

7. Jiang GL, Tucker SL, Guttenberger R, Peters LJ, Morrison WH, et al. (1994) Radiation-induced injury to the visual pathway. Radiother Oncol 30: 17-25.

8. Nakissa N, Rubin P, Strohl R, Keys H (1983) Ocular and orbital complications following radiation therapy of paranasal sinus malignancies and review of literature. Cancer 51: 980-986.

9. Parsons JT, Bova FJ, Fitzgerald CR, Mendenhall WM, Million RR (1994) Radiation optic neuropathy after megavoltage external-beam irradiation: analysis of time-dose factors. Int J Radiat Oncol Biol Phys 30: 755-763.

10. Parsons JT, Fitzgerald CR, Hood Cl, Ellingwood KE, Bova FJ, et al. (1983) The effects of irradiation on the eye and optic nerve. Int J Radiat Oncol Biol Phys 9: 609-622.

11. Takeda A, Shigematsu N, Suzuki S, Fujii M, Kawata T, et al. (1999) Late retina complications of radiation therapy for nasal and paranasal malignancies: relationship between irradiated-dose area and severity. Int J Radiat Oncol Biol Phys 44: 599-605

12. Cackett P, Stebbing J, Dhillon B (2003) Complications of therapy and a diagnostic dilemma case. Case 1. Radiation maculopathy following treatment of nasopharyngeal carcinoma. J Clin Oncol 21: 4650-4651.

13. Wijers OB, Levendag PC, Luyten GP, Bakker BA, Freling NJ, et al. (1999) Radiation-induced bilateral optic neuropathy in cancer of the nasopharynx. Case failure analysis and a review of the literature. Strahlenther Onkol 175 21-27.

14. Monroe AT, Bhandare N, Morris CG, Mendenhall WM (2005) Preventing radiation retinopathy with hyperfractionation. Int J Radiat Oncol Biol Phys 61 : 856-864.

15. Archer DB, Amoaku WM, Gardiner TA (1991) Radiation retinopathy--clinical, histopathological, ultrastructural and experimental correlations. Eye (Lond) 5 : 239-251.

16. Malik A, Golnik K (2012) Hyperbaric oxygen therapy in the treatment of radiation optic neuropathy. J Neuroophthalmol 32: 128-131.

17. Zamber RW, Kinyoun JL (1992) Radiation retinopathy. West J Med 157: 530 533.

18. Kline LB, Kim JY, Ceballos R (1985) Radiation optic neuropathy. Ophthalmology 92: $1118-1126$

19. Carvounis PE, Katz B (2003) Gamma knife radiosurgery in neuroophthalmology. Curr Opin Ophthalmol 14: 317-324.

20. Hayreh SS (1970) Post-radiation retinopathy. A fluorescence fundus angiographic study. Br J Ophthalmol 54: 705-714.

21. Finger PT, Kurli M (2005) Laser photocoagulation for radiation retinopathy afte ophthalmic plaque radiation therapy. Br J Ophthalmol 89: 730-738.

22. Lee MS, Borruat FX (2011) Should patients with radiation-induced optic neuropathy receive any treatment? J Neuroophthalmol 31: 83-88. 